\title{
Internal Damper Characteristics of Rotor System with Submerged ER Fluid Journal Bearing
}

\author{
SIYOUL JANG ${ }^{\mathrm{a}, *}$ and JOHN A. TICHY ${ }^{\mathrm{b}}$ \\ aLab. for Manufacturing and Productivity, Massachusetts Institute of Technology, Cambridge MA 02139, USA; ${ }^{\mathrm{b}}$ Dept. of Mechanical \\ Engineering \& Mechanics, and Aeronautical Engineering, Rensselaer Polytechnic Institute, Troy NY 12180-3590, USA
}

(Received 22 April 1996; In final form 22 April 1996)

\begin{abstract}
Electro-Rheological (ER) fluid behavior is similar to Bingham fluid's. Only when the shear stress magnitude of ER fluid exceeds the yield stress, Newtonian flow results. Continuous shear strain rate equation about shear stress which simulates Bingham-like fluid shows viscosity variations. Shear yield stress is controlled by electric fields. Electric fields in circumferential direction around the journal are also changeable because of gap distance. These values make changes of spring and damping coefficients of journal bearings compared to Newtonian flow case. Implicit viscosity variation effects according to shear strain rates of fluid are included in generalized Reynolds' equation for submerged journal bearing. Fluid film pressure and perturbation pressures are solved using switch function of Elord's algorithm for cavitation boundary condition. Spring and damping coefficients are obtained for several parameters that determine the characteristics of ER fluids under a certain electric field. From these values stability region for simple rotor-bearing system is computed. It is found that there are no big differences in load capacities with the selected electric field parameters at low eccentric region and higher electric field can support more load with stability at low eccentric region.
\end{abstract}

Keywords: Electro-Rheological Fluid, Dynamic Coefficient, Reynolds' Equation, Bingham Fluid, Switch Function, Rotor-Bearing System Stability

\section{INTRODUCTION}

Electro-Rheological fluid (ER fluid) changes its rheology of dispersions upon application of electric fields. Higher fields make this ER fluid behavior as solid. Winslow [1947] observed that applying strong electric fields to non-aqueous silica suspensions acti- vated with a small amount of water caused rapid solidification of the originally fluid material. Electrically induced formation of fibrous particle chains increase the viscosity of the suspension that grows as the square of the electric field.

ER fluid behavior is very similar to Bingham fluid model, which is characterized by two parameters: a

\footnotetext{
*Corresponding author. Tel.: 617-253-0235. Fax: 617-258-6156. E-mail: JANGS@ MIT.EDU.
} 
yield stress and a viscosity. It shows the characteristic of quasi-Newtonian fluid once sheared. Before it is sheared, it has resistance, yield stress which is related to the square of the applied electric field. Bingham fluid which has a discontinuity at $\dot{\gamma}=0$ has been analyzed for ER fluid journal bearing by Dimarogonas and Kollias [1992]. They impose some restrictions on solving non-linear Reynolds equation as the velocity profile is always positive. Tichy [1992] has generalized the case of lubrication theory with Bingham materials in the form of various modified Reynolds equations, depending on the core conditions. Continuous Bingham-like fluid model by Dorier and Tichy [1992] is proposed with yield stress parameter $\tau_{o}$, strain rate parameter $\dot{\gamma}_{O}$ and viscosity $\mu_{0}$. This model uses a rheological equation which is continuous and can be applied uniformly over the entire flow domain. It can simulate actual shear stress-strain relationship [1989] of ER fluid which is rather continuous at shear rate $\dot{\gamma}=0$ upon application of electric field.

Many researches of ER fluid have been applied in mechanical components such as valve, clutch, brake, Calson et al. [1991] and automobile shock absorber, Bhadra et al. [1989], because Bingham fluid effect upon the application of voltage replaces many mechanical link systems and it responses very quickly. What is more, the fluid can be actively controlled. Morishita and Mitsui [1989] worked on the performance of a prototype squeeze-film damper.

This discussion focuses on an electronically controlled journal bearing which supports rotor system of mass $2 m_{a}$ and uses ER fluid as lubricant. Generalized non-Newtonian Reynolds equation for submerged journal bearing is solved with continuous stress-strain Bingham-like constitutive equation. The objective is to demonstrate the viability of ER technology in journal bearing with internal damper characteristics. The reasons are that 1) ER effect is very efficient, typically requiring only a few watts of electrical power 2 ) the device construction is simplified due to the non mechanical nature of ER technology, potentially decreasing manufacturing cost and increasing reliability 3) the ER effect provides the fast response.

\section{ANALYSIS}

\section{Fluid Film Pressure with ER Lubricant}

To describe ER fluid behavior as continuous Bingham-like fluid, three material parameters are proposed, in Eq. (1): yield stress parameter $\tau_{0}$, strain rate parameter $\dot{\gamma}_{O}$ and viscosity $\mu_{0}$. Electric field changes the magnitude of yield stress $\tau_{O}$ and high value of strain parameter $\dot{\gamma}_{O}$ makes the fluid behavior more ideal Bingham fluid as shown Figure 1. Winslow [1947] and many other researchers have considered that ER fluid has a yield stress proportional to the square of applied electric field. However, the measured shear stress increases parabolically only in the low electric field strength range and then shows linear relationship at higher electric field over $2.0 \mathrm{KV} /$ $\mathrm{mm}$. High level of electric field is thought to generate realistic and practical field strength. In this work, linear relationship between yield shear stress and electric field is simulated with Eq. (1) for the investigation of a more practical engineering application. Yield stress parameter $\tau_{O}$ implies electric field $E=$ $V / h(\theta, y)$. This rheological equation represents continuous relationship between strain and stress and can be applied over the entire flow domain.

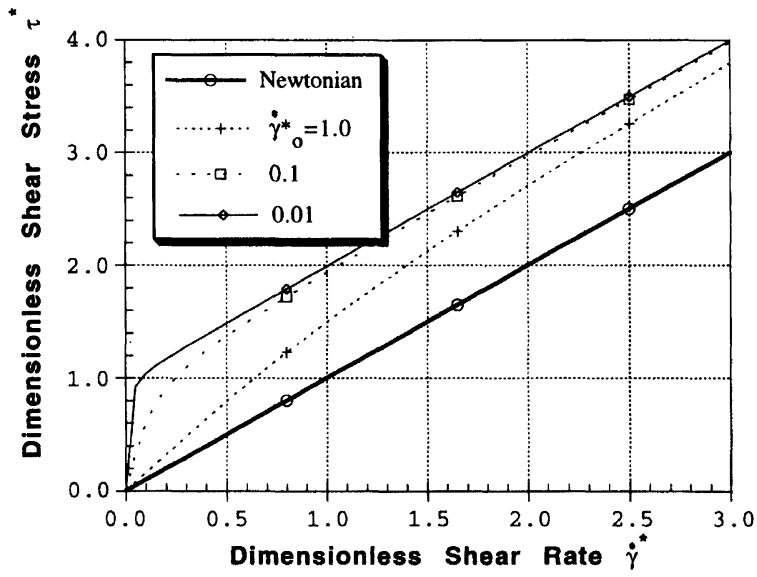

FIGURE 1 Dorier-Tichy continuous Bingham-like fluid model. 


$$
\mu(\dot{\gamma})=\mu_{0}+\frac{2 \tau_{0}}{\pi \dot{\gamma}} \arctan \left(\frac{\dot{\gamma}}{\dot{\gamma}_{0}}\right)
$$

Yield stress value $\tau_{0}$ varies around the journal surface as the journal center is located with eccentricity. This value makes changes of viscosity along the journal circumference even under the same applying voltage. Viscosity is also a function of shear rate as the journal rotates. With this viscosity constitutive equation, new Reynolds' equation should be derived for the fluid pressure and dynamic coefficients of the journal bearing. The governing equation is expressed by the deviatoric stress $\tau_{i j}$ which is related to the deformation rate $\dot{\gamma}_{i j}$ by a viscosity function $\mu(\dot{\gamma})$.

For the lubrication geometry of journal bearing illustrated in Figure 2, the non-linear relationship between shear rate and shear stress (2), momentum equation (3) and continuity equation (4) can be explained as below.

$$
\begin{gathered}
\tau_{x z}(x, y, z)=\mu(\dot{\gamma}) \frac{\partial u}{\partial z}, \tau_{y z}(x, y, z)=\mu(\dot{\gamma}) \frac{\partial v}{\partial z}, \\
\frac{\partial \tau_{x z}}{\partial z}=\frac{\partial p(x, y)}{\partial x}, \frac{\partial \tau_{y z}}{\partial z}=\frac{\partial p(x, y)}{\partial y}, \\
\frac{\partial(\rho u)}{\partial x}+\frac{\partial(\rho v)}{\partial x}+\frac{\partial(\rho w)}{\partial x}=0
\end{gathered}
$$

where $p^{*}\left(\theta, y^{*}\right)$ is the fluid film pressure.

The shear rate magnitude $|\dot{\gamma}|$ is

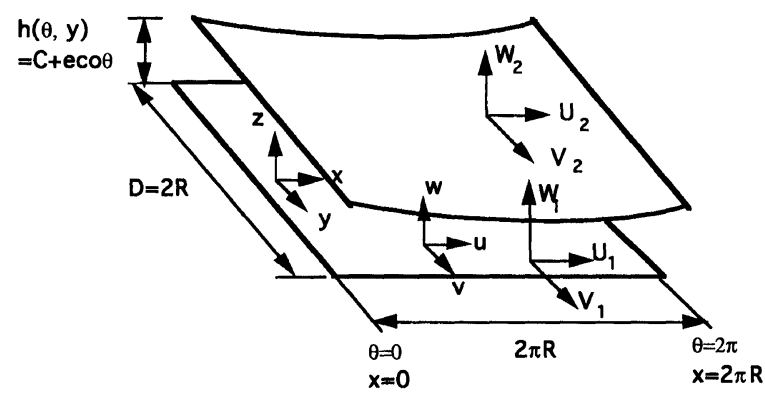

FIGURE 2 Schematic diagram of bearing geometry.

$$
|\dot{\gamma}|=\sqrt{\left(\frac{\partial u}{\partial z}\right)^{2}+\left(\frac{\partial w}{\partial z}\right)^{2}}
$$

Using the boundary conditions below, shear stressstrain relationship, momentum equation and continuity equation, the expression of shear rate Eq. (7) is obtained.

Boundary conditions for the velocity are

$$
\begin{aligned}
& u(x, y, h)=U_{1}, v(x, y, h)=V_{1}, w(x, y, h)=W_{1}, \\
& u(x, y, h)=U_{2}, v(x, y, h)=V_{2}, w(x, y, h)=W_{2} .
\end{aligned}
$$

The magnitude of shear rate is expressed by

$$
\begin{gathered}
\dot{\gamma}^{2}=\frac{1}{\mu^{2} \dot{\gamma}}\left[\left\{\frac{\partial p}{\partial x}\left(z-\frac{f_{1}(h)}{f_{2}(h)}\right)+\frac{U_{2}-U_{1}}{f_{2}(h)}\right\}^{2}+\left\{\frac{\partial p}{\partial y}\right.\right. \\
\left.\left.\left(z-\frac{f_{1}(h)}{f_{2}(h)}\right)+\frac{V_{2}-V_{1}}{f_{2}(h)}\right\}^{2}\right],
\end{gathered}
$$

where,

$$
f_{1}(z ; x, y)=\int_{0}^{z} \frac{z^{\prime}}{\mu(\dot{\gamma})} d z^{\prime}, \text { and } f_{2}(z ; x, y)=\int_{0}^{z} \frac{1}{\mu(\dot{\gamma})} d z^{\prime}
$$

Knowing the variation of the shear rate $\dot{\gamma}$ across the gap, the velocity can be found by the following expressions:

$$
\begin{aligned}
& u(z ; x, y)=\frac{\partial p}{\partial x} f_{3}(z ; x, y)+\frac{U_{2}-U_{1}}{f_{2}(h ; x, y)}+U_{1}, \\
& v(z ; x, y)=\frac{\partial p}{\partial y} f_{3}(z ; x, y)+\frac{V_{2}-V_{1}}{f_{2}(h ; x, y)}+V_{1},
\end{aligned}
$$

where $f_{3}(z ; x, y)=f_{1}(z ; x, y)-\frac{f_{1}(h ; x, y)}{f_{2}(h ; x, y)} f_{2}(z ; x, y)$.

From the expressions of velocities and continuity equation, dimensionless Reynolds' equation, Eq. (11) is obtained for the journal bearing geometry with the following dimensionless variables and parameters: 


$$
\begin{aligned}
& \frac{\partial}{\partial \theta}\left\{h^{*^{3}} f_{4}^{*}\left(1 ; \theta, y^{*}\right) \frac{\partial\left(g\left(\theta, y^{*}\right) p^{*}\right)}{\partial \theta}\right\} \\
& +\frac{\partial}{\partial y}\left\{h^{*^{3}} f_{4}^{*}\left(1 ; \theta, y^{*}\right) \frac{\partial\left(g\left(\theta, y^{*}\right) p^{*}\right)}{\partial y^{*}}\right\} \\
& =\frac{\partial}{\partial \theta}\left\{h^{*} f_{5}^{*}\left(1 ; \theta, y^{*}\right)\right\}-\frac{\partial h^{*}}{\partial \theta}-\frac{\partial h^{*}}{\partial t^{*}} .
\end{aligned}
$$

The dimensionless variables and parameters are

$$
\begin{gathered}
\theta=\frac{x}{R}, y^{*}=\frac{y}{R}, z^{*}=\frac{z}{h}, \mu^{*}=\frac{\mu}{\mu_{0}}, \gamma_{0}^{*}=\frac{\omega \dot{\gamma}_{0}}{\psi_{\min }^{2}}, \\
\tau_{0}^{*}=\frac{\psi_{\min \tau_{0}}^{2}}{\mu_{0} \omega}, h^{*}=\frac{h}{C}=1+\varepsilon \cos (\theta-\Phi), p^{*} \\
=\frac{\psi_{\min }^{2} p}{\mu_{0} \omega} .
\end{gathered}
$$

$$
\begin{aligned}
& \text { where } \begin{aligned}
& f_{1}^{*}\left(1 ; \theta, y^{*}\right)=\frac{\mu_{0}}{h^{2}} f_{1}(h ; x, y), \\
& f_{2}^{*}\left(1 ; \theta, y^{*}\right)=\frac{\mu_{0}}{h} f_{2}(h ; x, y), \\
& f_{3}^{*}\left(z^{*} ; \theta, y^{*}\right)=\frac{\mu_{0}}{h^{2}} f_{3}(z ; x, y)=\frac{\mu_{0}}{h^{2}}\left(f_{1}(z ; x, y)\right. \\
&\left.-\frac{f_{1}(h ; x, y)}{f_{2}(h ; x, y)} f_{2}(z ; x, y)\right), \\
& f_{4}^{*}\left(1 ; \theta, y^{*}\right)=\frac{\mu_{0}}{h^{3}} f_{4}(h ; x, y)=\frac{\mu_{0}}{h^{3}} \int_{0}^{h} f_{3}\left(z^{\prime} ; x, y\right) d z^{\prime}, \\
& f_{5}^{*}\left(1 ; \theta, y^{*}\right)=\frac{1}{h} f_{5}(h ; x, y)=\frac{1}{h f_{2}(h ; x, y)} \int_{0}^{h} f_{2} \\
&\left(z^{\prime} ; x, y\right) d z^{\prime} .
\end{aligned}
\end{aligned}
$$

When the dimensionless viscosity $\mu\left(\theta, y^{*}, z^{*}\right)$ is equal to 1 , it represents Newtonian fluid. With the known initial Newtonian pressure profiles and shear rate, the implicit value of shear rate, Eq. (7) is solved using a relaxation method. Converged values of shear rate $\dot{\gamma}^{*}\left(\theta, y^{*}, z^{*}\right)$ generate new values of viscosity across film distance. Calculations of viscosity functions $f_{i}^{*}\left(x^{*}, y^{*}, z^{*}\right)$ 's have been performed after the values of $\mu^{*}\left(\theta, y^{*}, z^{*}\right)$ are obtained. Dimensionless Reynolds' equation is iterated for a new pressure field. After viscosity functions are computed with the converged values of shear rate across the film thick- ness, the linear algebraic system of Reynolds' equation is established by finite difference method. It is solved with successive over-relaxation (SOR) method for the unknown values of pressure $p^{*}\left(\theta, y^{*}\right)$. For the implicit solution of pressures in this Reynolds' equation, there are two convergence criteria: one is for the shear rate across the film gap and the other is fluid film pressure.

$$
\begin{aligned}
\left|\frac{\dot{\gamma}^{* n}\left(\theta, y^{*}, z^{*}\right)-\dot{\gamma}^{* n-1}\left(\theta, y^{*}, z^{*}\right)}{\dot{\gamma}^{* n}\left(\theta, y^{*}, z^{*}\right)}\right| & \leq 0.001, \\
\left|\frac{p^{* n}\left(\theta, y^{*}\right)-p^{* n-1}\left(\theta, y^{*}\right)}{p^{* n}\left(\theta, y^{*}\right)}\right| & \leq 0.001
\end{aligned}
$$

where $n$ is the iteration number.

The boundary condition at both sides of the journal bearing is

$$
p^{*}\left(\theta, \pm \frac{B}{D}\right)=P_{\text {sup }}
$$

where $P_{\text {sup }}$ is the supplied oil pressure for the submerged journal bearing.

For the computational purpose, the periodic conditions are maintained by equating values of $p^{*}\left(\theta, y^{*}\right)$ on the boundaries at $\theta=0$ and $2 \pi$ for iteration $n+$ $l$ as the average of neighboring values in the interior for the previous iteration $n$ :

$$
\begin{gathered}
p^{*}\left(0, y^{*}\right)_{n+1}=p^{*}\left(2 \pi, y^{*}\right)_{n+1} \\
=\frac{p^{*}\left(0+\delta \theta, y^{*}\right)_{n}+p^{*}\left(2 \pi-\delta \theta, y^{*}\right)_{n}}{2} .
\end{gathered}
$$

When the film rupture occurs in the divergent film region, the location of the trailing end boundary is governed by the condition of zero pressure gradient and zero pressure. This condition can be satisfied using the switch function $g\left(\theta, y^{*}\right)$, Elord [1981].

$$
\begin{gathered}
g(\theta, y)=1 ; \text { non-cavitation region, } p^{*}\left(\theta, y^{*}\right)>P_{\text {sup }}, \\
g\left(\theta, y^{*}\right)=0 ; \text { cavitation region, } p^{*}\left(\theta, y^{*}\right)=P_{\text {sup }}
\end{gathered}
$$


As long as $g\left(\theta, y^{*}\right)$ is known, the solution obtained by Eq. (11) would automatically satisfy cavitation boundary condition.

The load components in the $\mathrm{x}$ and $\mathrm{y}$ directions are computed by integrating the values of pressure $p^{*}\left(\theta, y^{*}\right)$ over the bearing area.

$$
\begin{aligned}
& W_{x}^{*}=\frac{1}{4 B / D} \int_{0}^{2 \pi} \int_{-B / D}^{B / D} p^{*}\left(\theta, y^{*}\right) \cos \theta d y^{*} d \theta, \\
& W_{z}^{*}=\frac{1}{4 B / D} \int_{0}^{2 \pi} \int_{-B / D}^{B / D} p^{*}\left(\theta, y^{*}\right) \sin \theta d y^{*} d \theta .
\end{aligned}
$$

The resultant load and the attitude angle are obtained as following:

$$
W^{*}=\sqrt{W_{x}^{*}+W_{z}^{*}},
$$

and

$$
\Phi=\arctan \left(\frac{W_{z}^{*}}{W_{x}^{*}}\right) .
$$

The dimensionless load capacity (Sommerfeld number) which is a function of eccentricity ratio and $B / D$ value is expressed as below:

$$
S o=\frac{F_{s t a t} \psi_{\min }^{2}}{B D \mu_{0} \omega}=W^{*} .
$$

\section{Calculation of Dynamic Coefficients}

It is found that the reaction forces are functions of $x^{*}$ and $z^{*}$ and of the instaneous journal center velocities, $\frac{\partial x^{*}}{\partial t^{*}}$ and $\frac{\partial z^{*}}{\partial t^{*}}$ when disturbance is occurred about equilibrium point, Figure 3(a). The linearized spring and damping coefficients are obtained by perturbation method about a quasi-steady-state journal position. Figure 3(a) represents the effect of changing load on the bearing's shaft position. For small amplitude mo- tions, $\Delta x^{*}$ and $\Delta z^{*}$ compared with the steady-state position $(\varepsilon, \Phi)$, the perturbed values of film thickness $h^{*}\left(\theta, y^{*}\right)$ and pressure $p^{*}\left(\theta, y^{*}\right)$ are expressed by a first order Taylor series expansion.

$$
\begin{gathered}
h^{*}\left(\theta, y^{*}\right)=h_{0}^{*}+\Delta x^{*} \cos \theta+\Delta z^{*} \sin \theta \\
h_{0}^{*}=1+\varepsilon \cos (\theta-\Phi) \\
\frac{\partial h^{*}}{\partial t^{*}}=\Delta \partial \dot{x^{*}} \cos \theta+\Delta \partial \dot{z}^{*} \sin \theta \\
p=p_{0}^{*}+\left(\frac{\partial p^{*}}{\partial x^{*}}\right)_{0} \Delta x^{*}+\left(\frac{\partial p^{*}}{\partial x^{*}}\right)_{0} \Delta z^{*}+\left(\frac{\partial p^{*}}{\partial \dot{x^{*}}}\right)_{0} \Delta \dot{x}^{*} \\
+\left(\frac{\partial p^{*}}{\partial \dot{z}^{*}}\right)_{0} \Delta \dot{z}^{*}
\end{gathered}
$$

By substituting equations (23a,b,c,d) into Reynolds' Eq. (11) and arranging it for the first order terms only, five equations are obtained:

$$
\begin{gathered}
\frac{\partial}{\partial \theta}\left\{h_{0}^{* 3} f_{4}^{*}(1) \frac{\partial\left(g\left(\theta, y^{*}\right) p_{0}^{*}\right)}{\partial \theta}\right\} \\
+\frac{\partial}{\partial y^{*}}\left\{h_{0}^{* 3} f_{4}^{*}(1) \frac{\partial\left(g\left(\theta, y^{*}\right) p_{0}^{*}\right)}{\partial y^{*}}\right\}=\frac{\partial}{\partial \theta}\left\{h_{0}^{*} f_{5}^{*}(1)\right\}-\frac{\partial h_{0}^{*}}{\partial \theta}, \\
\frac{\partial}{\partial \theta}\left\{h_{0}^{* 3} f_{4}^{*}(1) \frac{\partial\left(g\left(\theta, y^{*}\right) p_{x^{*}}^{*}\right)}{\partial \theta}\right\} \\
+\frac{\partial}{\partial y^{*}}\left\{h_{0}^{* 3} f_{4}^{*}(1) \frac{\partial\left(g\left(\theta, y^{*}\right) p_{x^{*}}^{*}\right)}{\partial y^{*}}\right\} \\
=\frac{\partial}{\partial \theta}\left\{f_{5}^{*}(1) \cos \theta\right\}+\sin \theta-3\left(\frac{\cos \theta}{h_{0}^{*}}\right) \\
\left(\frac{\partial\left(h_{0}^{*} f_{5}^{*}(1)\right)}{\partial \theta}-\frac{\partial h_{0}^{*}}{\partial \theta}\right)-3 h_{0}^{* 3} f_{4}^{*}(1) \frac{\partial h_{0}^{* 3}}{\partial \theta} \frac{\partial}{\partial \theta}\left(\frac{\cos \theta}{h_{0}^{*}}\right) \\
\frac{\partial}{\partial \theta}\left\{h_{0}^{* 3} f_{4}^{*}(1) \frac{\partial\left(g\left(\theta, y^{*}\right) p_{z^{*}}^{*}\right)}{\partial \theta}\right\} \\
\frac{\partial}{\partial y^{*}}\left\{h_{0}^{* 3} f_{4}^{*}(1) \frac{\partial\left(g\left(\theta, y^{*}\right) p_{z^{*}}^{*}\right)}{\partial y^{*}}\right\}
\end{gathered}
$$




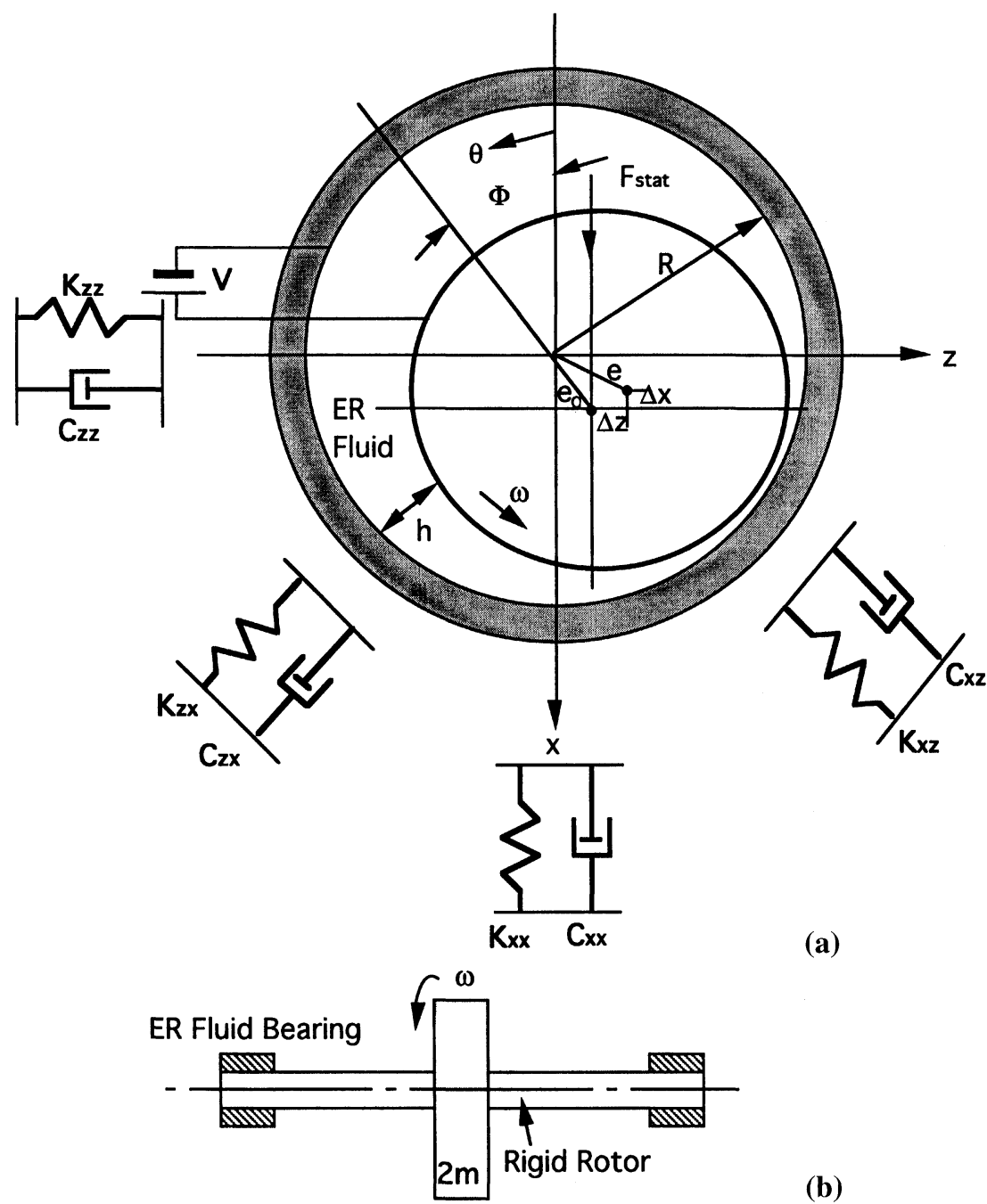

FIGURE 3 (a), (b) Rotor-bearing system.

$$
\begin{gathered}
=\frac{\partial}{\partial \theta}\left\{f_{5}^{*}(1) \cos \theta\right\}-\cos \theta-3\left(\frac{\sin \theta}{h_{0}^{*}}\right)\left(\frac{\partial\left(h_{0}^{*} f_{5}^{*}(1)\right)}{\partial \theta}\right. \\
\left.-\frac{\partial h_{0}^{*}}{\partial \theta}\right)-3 h_{0}^{* 3} f_{4}^{*}(1) \frac{\partial h_{0}^{* 3}}{\partial \theta} \frac{\partial}{\partial \theta}\left(\frac{\sin \theta}{h_{0}^{*}}\right) \\
\frac{\partial}{\partial \theta}\left\{h_{0}^{* 3} f_{4}^{*}(1) \frac{\partial\left(g\left(\theta, y^{*}\right) p_{x^{*}}^{*}\right)}{\partial \theta}\right\} \\
+\frac{\partial}{\partial y^{*}}\left\{h_{0}^{* 3} f_{4}^{*}(1) \frac{\partial\left(g\left(\theta, y^{*}\right) p_{x^{*}}^{*}\right)}{\partial y^{*}}\right\}=-\cos \theta
\end{gathered}
$$

$$
\begin{gathered}
\frac{\partial}{\partial \theta}\left\{h_{0}^{* 3} f_{4}^{*}(1) \frac{\partial\left(g\left(\theta, y^{*}\right) p_{z^{*}}^{*}\right)}{\partial \theta}\right\} \\
+\frac{\partial}{\partial y^{*}}\left\{h_{0}^{* 3} f_{4}^{*}(1) \frac{\partial\left(g\left(\theta, y^{*}\right) p_{z^{*}}^{*}\right)}{\partial y^{*}}\right\}=-\sin \theta .
\end{gathered}
$$

$(24 a, b, c, d, e)$

Once the steady-state pressure from (24 a) is obtained, it can be used in obtaining the perturbation pressures ( $24 \mathrm{~b}, \mathrm{c}, \mathrm{d}, \mathrm{e})$, which have the same forms as Eq. (24 a). The boundary conditions for the perturbation pressures at both sides of bearing, $\theta=0$ and 
$2 \pi$ are the same as explained previously. Around the cavitation boundary, the perturbation pressures are computed in the same way as steady-state pressure by using the switch function $g\left(\theta, y^{*}\right)$.

Dimensionless dynamic coefficients are obtained by integrating the values of the perturbation pressures over the bearing area as followings:

$$
\begin{aligned}
& \left\{\begin{array}{ll}
K_{X X}^{*} & K_{X Z}^{*} \\
K_{Z X}^{*} & K_{Z Z}^{*}
\end{array}\right\} \\
& =\frac{1}{4 B / D} \int_{0}^{2 \pi} \int_{-B / D}^{B / D}\left\{\begin{array}{lll}
p_{X^{*}}^{*} & \cos \theta & p_{Z^{*}}^{*} \cos \theta \\
p_{X^{*}}^{*} \sin \theta & p_{Z^{*}}^{*} \sin \theta
\end{array}\right\} d y^{*} d \theta, \\
& \left\{\begin{array}{ll}
B_{X X}^{*} & B_{X Z}^{*} \\
B_{Z X}^{*} & B_{Z Z}^{*}
\end{array}\right\} \\
& =\frac{1}{4 B / D} \int_{0}^{2 \pi} \int_{-B / D}^{B / D}\left\{\begin{array}{c}
p_{X^{*}}^{*} \cos \theta p_{Z^{*}}^{*} \cos \theta \\
p_{X^{*}}^{*} \sin \theta p_{Z^{*}}^{*} \sin \theta
\end{array}\right\} d y^{*} d \theta .
\end{aligned}
$$

\section{Journal Bearing Stability}

Consider a shaft of mass $2 m_{a}$ supported by two identical well-aligned journal bearings, Figure 3(b). The

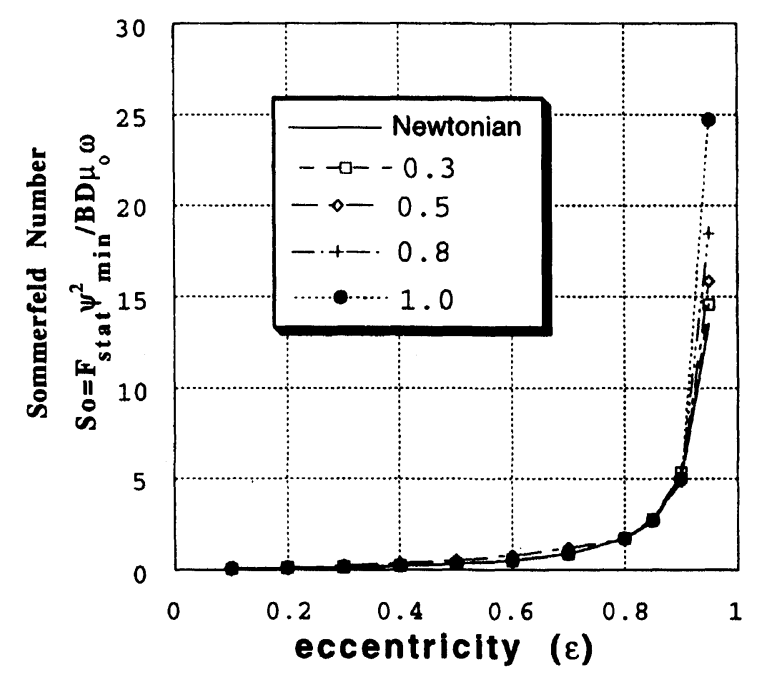

FIGURE 4 Load capacity (Sommerfeld number) as eccentricity ratio and electric field. linearized equation of journal motion is expressed as below:

$$
\begin{aligned}
& \left\{\begin{array}{cc}
m_{a} & 0 \\
0 & m_{a}
\end{array}\right\}\left\{\begin{array}{c}
\Delta \ddot{x} \\
\ddot{\Delta}
\end{array}\right\}+\frac{S o}{C \omega}\left\{\begin{array}{l}
B_{X X} B_{X Z} \\
B_{Z X} B_{Z Z}
\end{array}\right\}\left\{\begin{array}{l}
\Delta \dot{x} \\
\Delta \dot{z}
\end{array}\right\} \\
& +\frac{S o}{C}\left\{\begin{array}{l}
K_{X X} K_{X Z} \\
K_{Z X}
\end{array} K_{Z Z}\right\}\left\{\begin{array}{l}
\Delta x \\
\Delta z
\end{array}\right\}=\left\{\begin{array}{l}
0 \\
0
\end{array}\right\} \text {. }
\end{aligned}
$$

The solution to Eq. (27) has the form of

$$
\left\{\begin{array}{l}
\Delta x \\
\Delta z
\end{array}\right\}=\left\{\begin{array}{l}
x_{h} \\
z_{h}
\end{array}\right\} \exp (\Omega t \omega)
$$

Substituting Eq. (28) into (27) provides

$$
\begin{gathered}
\left\{\begin{array}{cc}
M_{a}+\bar{\Omega} B_{X X}+K_{X X} & \bar{\Omega} B_{X Z}+K_{X Z} \\
\bar{\Omega} B_{Z X}+K_{Z X} & M_{a}+\bar{\Omega} B_{Z Z}+K_{Z Z}
\end{array}\right\}\left\{\begin{array}{l}
x_{h} \\
z_{h}
\end{array}\right\} \\
\exp (\bar{\Omega} t \omega)=\left\{\begin{array}{l}
0 \\
0
\end{array}\right\},
\end{gathered}
$$

where $M_{a}=\frac{m_{a} C \Omega^{2}}{S o}$ and $\bar{\Omega}=\frac{\Omega}{\omega}=-\bar{\Omega}_{d}+i \bar{\Omega}_{v}$.

For a chosen static equilibrium position, the values of the coefficients are given, and setting the determinant equal to zero determines that the value of $M_{a}$ called $\left(M_{a}\right)_{c r}$, which makes the specified equilibrium position unstable. The solution for $\left(M_{a}\right)_{c r}$ and the associated whirl frequency, $\Omega^{2}=\left(\Omega_{V}\right)_{c r}^{2}$ are

$$
\begin{gathered}
\left(M_{a}\right)_{c r}\left(=\frac{C m_{a} \Omega^{2}}{S o}\right)\left(\Omega_{V}\right)_{c r}^{2} \\
=\frac{B_{X X} K_{Z Z}+K_{X X} B_{Z Z}-B_{Z X} K_{X Z}-B_{X Z} K_{Z X}}{B_{X X}+B_{Z Z}} \\
\left(\Omega_{V}\right)_{c r}^{2}=\frac{\left[K_{X X}-\left(M_{a}\right)_{c r}\right]\left[K_{Z Z}-\left(M_{a}\right)_{c r}\right]-K_{X Z} K_{Z X}}{B_{X X} B_{Z Z}-B_{X Z} B_{Z X}}
\end{gathered}
$$

When $M_{a}$ is smaller than $\left(M_{a}\right)_{c r}$, the system will be stable $\left(\bar{\Omega}_{d}>0\right)$. However, it will be unstable for $M_{a}$ larger than $\left(M_{a}\right)_{c r}$. Therefore, whether the bearing is susceptible to instability obviously depends on the 
values of the bearing coefficients, which in turn depend on the bearing type and the various performance parameters of these bearings.

\section{RESULTS}

Dimensionless value of shear yield stress $\tau_{0}^{*}$ indicates electric field strength. When angular velocity is 400 $\mathrm{rad} / \mathrm{s}, \psi_{\min }$ is $0.002, \mu_{0}$ is $0.0125 \mathrm{Pas}$ and $E$ is about $1.2 \mathrm{MV} / \mathrm{m}, \tau_{0}^{*}$ has the magnitude of about 1.0. This value of $\tau_{0}^{*}$ is within practical operation speed region. Load capacity, Figure 4 according to electric field strength show no big differences at low eccentricity, but over $\varepsilon=0.90$ large electric field strength makes high load capacity. The reasons are following: Shear strain rate under the operational angular velocity is so high that viscosity, Eq. (1) is álmost constant as Newtonian fluid case at low eccentricity in all cases. At high eccentricity, electric field is accelerated due to smaller gap and this makes higher yield shear stress. At this moment, immobile fluid layer near moving surface is formed to resist the fluid flow.

Spring coefficients $K_{i j}^{*} / \operatorname{So}(\varepsilon)$ show differences among the values of electric field strength $\tau_{0}^{*}$, Figure $5-8$. If eccentricity ratio is high above about 0.8 , all spring coefficients show irregular tendencies as high electric field.

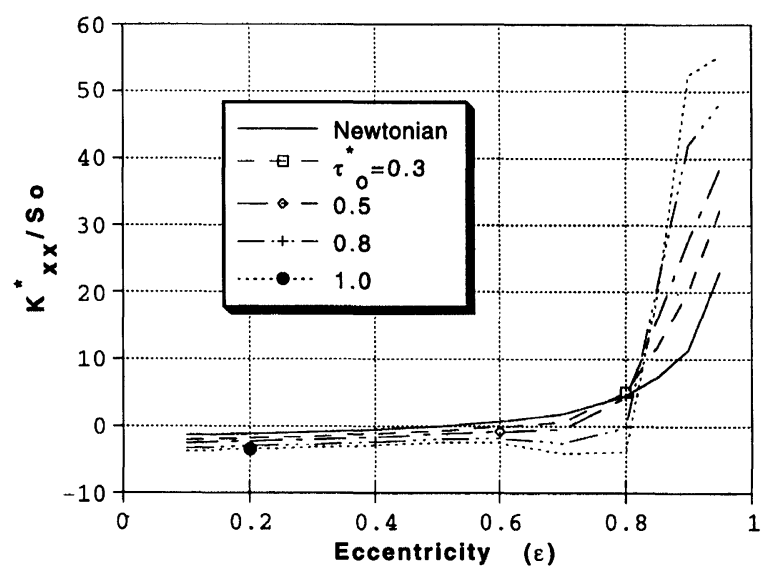

FIGURE 5 Spring coefficient of $\mathrm{K}_{x x}^{*} / \mathrm{So}$.

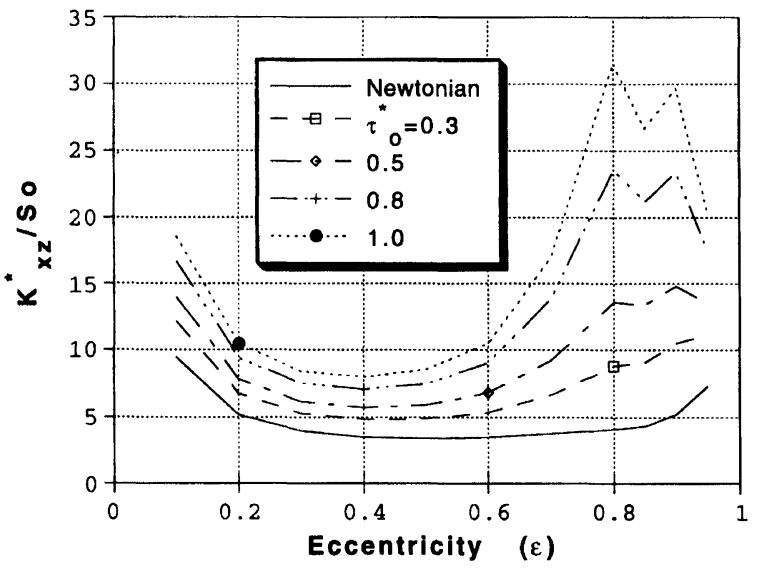

FIGURE 6 Spring coefficient of $\mathrm{K}_{x z}^{*} / \mathrm{So}$.

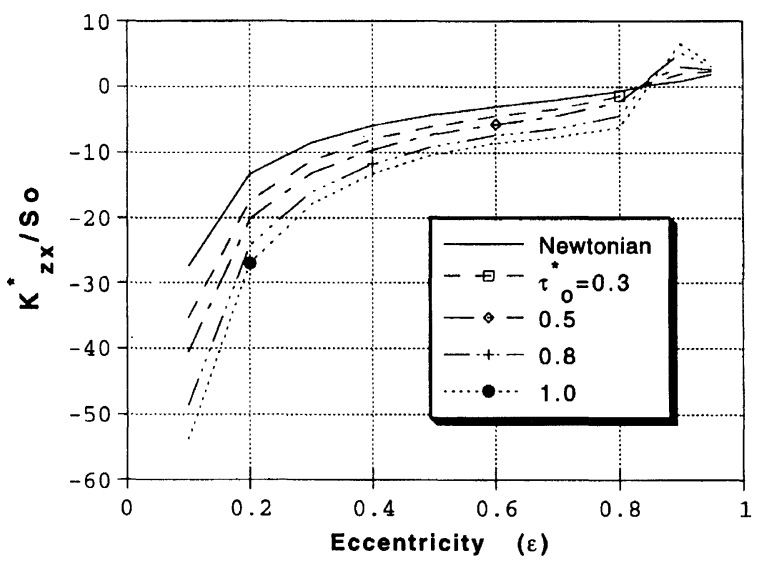

FIGURE 7 Spring coefficient of $\mathrm{K}_{z x}^{*} / \mathrm{S} o$.

Damping coefficients $B_{i j}^{*} / S o(\varepsilon)$ have different values according to electric field strength, Figure 9-12. Higher value of electric field strength gives high values of damping coefficient in all cases. As the case of spring coefficients, damping coefficients have irregular tendency above about $\varepsilon=0.8$.

Critical speed and mass parameter, Figure 13, 14 shows that at lower load capacity, high electric field can support more mass with stability. This means that stable region can be extended with the high electric field applied. But, at high load capacity $(\varepsilon$ is above $0.9)$ no electric field which is the case of Newtonian fluid can support more load with stability. 


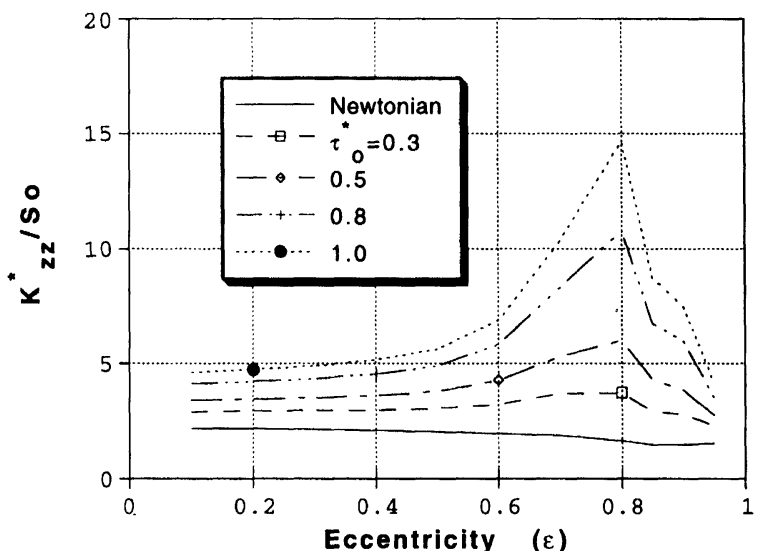

FIGURE 8 Spring coefficient of $\mathrm{K}_{z z}^{*} / \mathrm{S} o$.

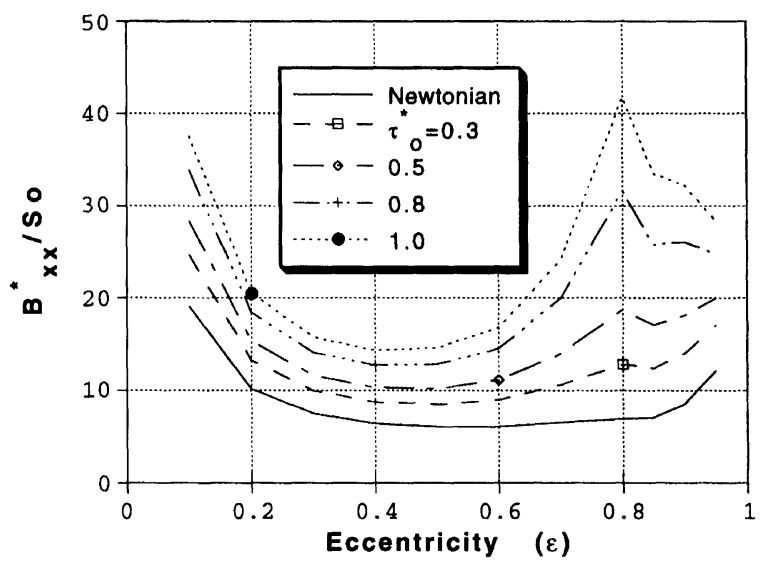

FIGURE 9 Damping coefficient of $\mathrm{B}_{x x}^{*} / \mathrm{S} o$.

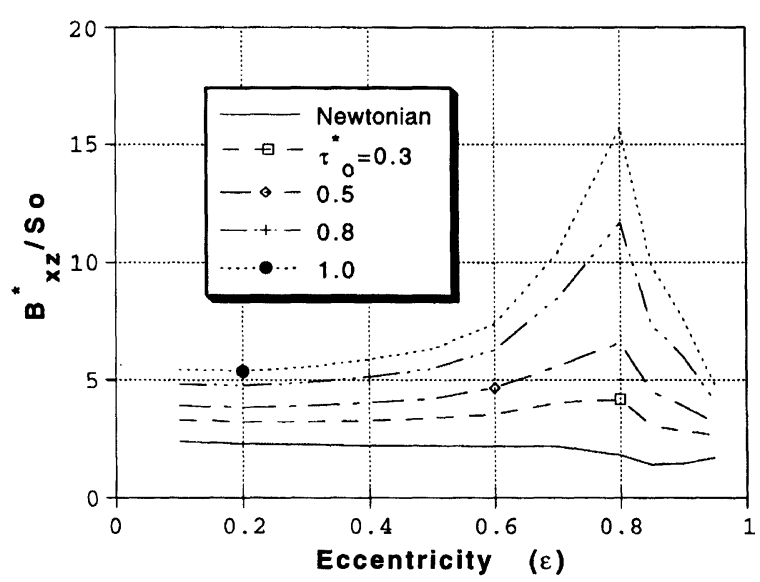

FIGURE 10 Damping coefficient of $\mathrm{B}_{x z}^{*} / \mathrm{S} o$

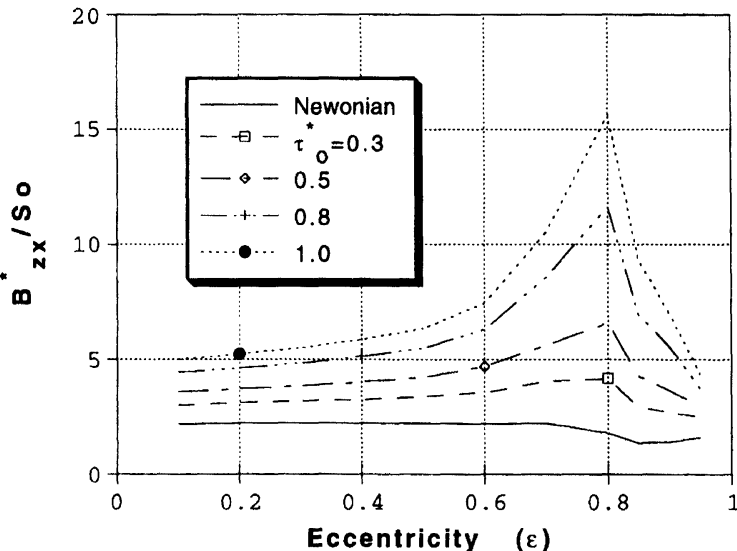

FIGURE 11 Damping coefficient of $\mathrm{B}_{z x}^{*} / \mathrm{S} o$

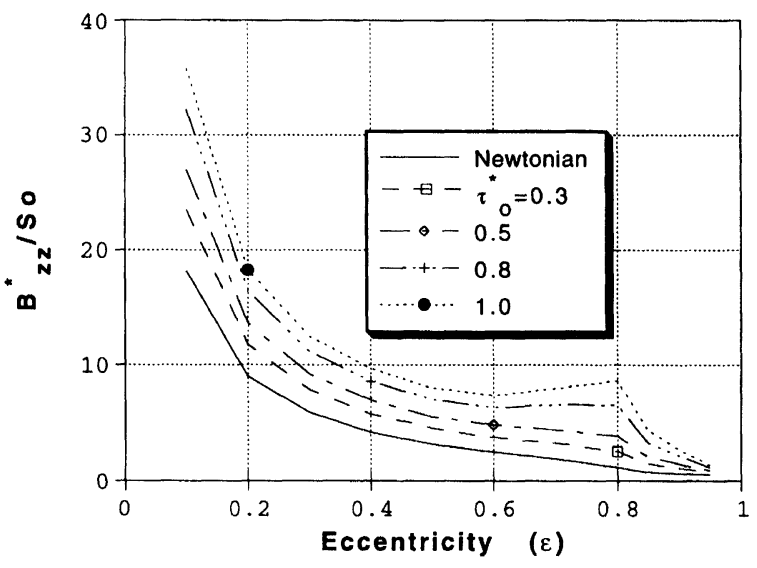

FIGURE 12 Damping coefficient of $\mathrm{B}_{z z}^{*} / \mathrm{S} o$.

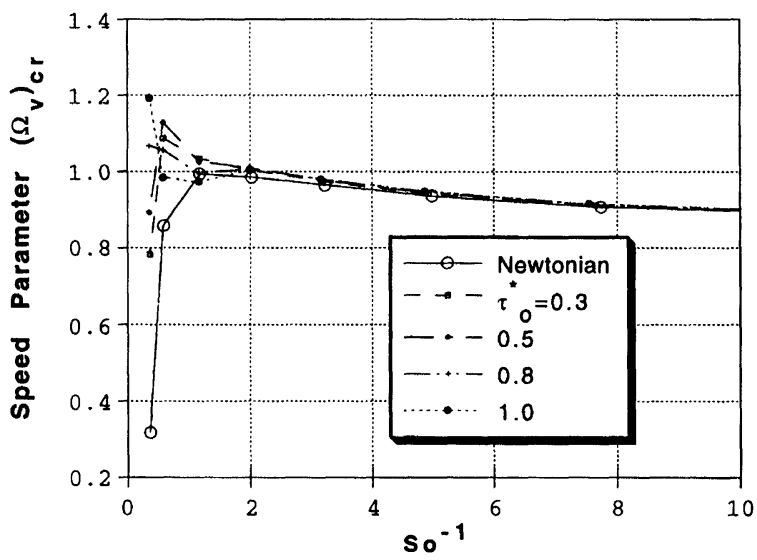

FIGURE 13 Critical speed parameter in the inverse value form of load capacity. 


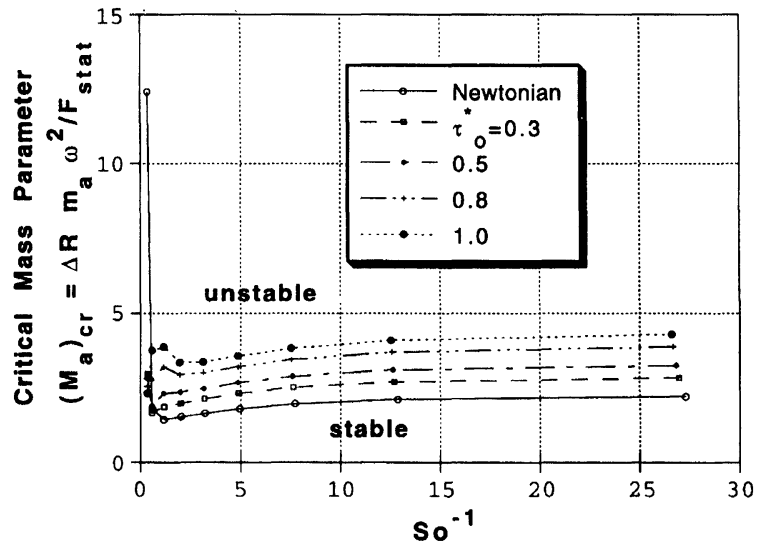

FIGURE 14 Critical mass parameter in the inverse value form of load capacity.

\section{CONCLUSION}

Active control of rotor dynamic behavior can be obtained by applying electric field on the bearing-journal surfaces. At low eccentricity ratio, high electric field can support more load with stability. On the other hand, discharging electric voltage can support more stable load at high eccentricity position.

As the matter of lubrication problem is concerned with ER fluid, it is also recommended that the journal bearing should be under operation at low eccentric position. The involved suspension particles for the solidification to electric charge may be entrapped into bearing or journal surface and it may cause many kinds of wear problems and collapse of rotor system although it can not be explained with numerical computation analysis. In order to get this system operated under low eccentric position, the bearing system should have a little larger dimension. But this can be compromised with the characteristics of internal damper, which eliminates physically external damper system.

\section{NOMENCLATURE}

$\begin{array}{ll}\text { B: } & \text { Bearing width }[\mathrm{m}] \\ B_{i j}: & \text { Damping coefficients }[\mathrm{N} \mathrm{s} / \mathrm{m}] \\ \text { D: } & \text { Bearing diameter }[\mathrm{m}]\end{array}$

$\mathrm{C}: \quad$ Bearing clearance $[\mathrm{m}]$

$f_{i}(x, y, z): \quad$ Viscosity functions

$\mathrm{g}(\theta, \mathrm{y}): \quad$ Switch function

$\mathrm{h}: \quad \quad$ Fluid film thickness $[\mathrm{m}]$

$K_{i j}$ : $\quad$ Spring coefficients $[\mathrm{N} / \mathrm{m}]$

$m_{a}: \quad$ Mass of rotor $\left[\mathrm{N} \mathrm{s}^{2} / \mathrm{m}\right]$

p: $\quad$ Fluid film pressure $\left[\mathrm{N} / \mathrm{m}^{2}\right]$

$\mathrm{R}$ : $\quad$ Bearing radius $[\mathrm{m}]$

So: $\quad$ Sommerfeld number

$\mathrm{u}, \mathrm{v}, \mathrm{w}$ : $\quad$ Fluid velocity in $\mathrm{x}, \mathrm{y}, \mathrm{z}$ directions $[\mathrm{m} / \mathrm{s}$ ]

$U_{i}, V_{i}, W_{i}: \quad$ Boundary velocity $[\mathrm{m} / \mathrm{s}]$

$W_{x}, W_{z}: \quad$ Load capacity

$\varepsilon: \quad$ Eccentricity of journal

$\Phi: \quad$ Attitude angle [rad]

$\dot{\gamma}_{0}$ : Shear rate parameter of Bingham-

like fluid $[1 / \mathrm{s}]$

$\dot{\gamma}: \quad$ Shear strain rate $[1 / \mathrm{s}]$

$\mu: \quad$ Viscosity $\left[\mathrm{N} \mathrm{s} / \mathrm{m}^{2}\right]$

$\theta$ : Dimensionless circumferential coor-

dinate on bearing [rad]

$\tau_{0}$ : Shear stress parameter of Binghamlike fluid $\left[\mathrm{N} / \mathrm{m}^{2}\right]$

$\tau: \quad$ Shear stress $\left[\mathrm{N} / \mathrm{m}^{2}\right]$

$\omega: \quad$ Angular velocity of rotor $[\mathrm{rad} / \mathrm{s}]$

$\Psi: \quad$ Clearance ratio $[\mathrm{C} / \mathrm{R}]$

Superscript*: Dimensionless values

Subscript $_{\mathbf{0}}$ : $\quad$ Reference values about equilibrium

\section{References}

Bhadra, D. K. and Harder, C. R. Electro-Viscous damping for Landing Aircraft, Proceedings of the Second International Conference on ER Fluids, edited by J. D. Calson, A. F. Spencher and H. Conrad, pp 402-408.

Calson, J. D. and Duclos, T. G. 1989, ER Fluid Clutches and Brakes-Fluid Property and Mechanical Design Considerations, ibid, pp. 353-367.

Diarogonas, A. and Kollias, A., 1992, Electrorheological FluidControlled Smart Journal Bearings, STLE, Vol. 35, pp. 611-618.

Dorier, C. and Tichy, J., 1992, Behavior of a Bingham-like Viscous Fluid in Lubrication Flows, Journal of Non-Newtonian Fluid Mechanics, 45, pp. 291-310.

Elrod, H. G., 1981, A Cavitation Algorithm, Journal of Tribology, Vol. 103, pp. 350-354

Glinicke, J. and Han, D-C. and Leonard, M., 1980, Practical Determination and Use of Bearing Dynamic Coefficients, Tribology International, pp. 297-309.

Jordan, T. C. and Shaw, M. T. 1991, Electrorheology, Material Rheology, MRS, Bulletin, pp 38-44, Vol. XVI, No. 8, pp. 38-44. 
Lund, J. W., 1987, Review of the Concept of Dynamic Coefficients for Fluid Film Journal Bearings, Journal of Tribology, Vol. 109 pp. $37-41$.

Tichy, J. 1991, Hydrodynamic Lubrication Theory of Bingham Plastic Flow Model, Journal of Rheology, 35(4), pp. 447-496. Oppermann, G., Penners, G., Schulze, M., Marquarrdt, G. and Flindt, R. 1989, Applications of Electroviscous Fluids as Movement Sensor Control Devices in Active Vibration Dampers, Pro- ceedings of the Second International Conference on ER Fluids, edited by J. D. Calson, A. F. Spencher and H. Conrad, pp. 287299.

Winslow, W. M., 1947, Method and Means of Translating Electrical Impulses into Mechanical Force, U.S. Patent 2, 147, 750. 


\section{ait \\ ENERGY MATERIALS}

M A N E Y publishing

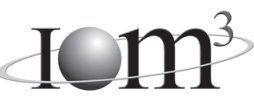

\section{Materials Science \& Engineering for Energy Systems}

Maney Publishing on behalf of the Institute of Materials, Minerals and Mining

The Institute of Materials, Minerals \& Mining

Economic and environmental factors are creating ever greater pressures for the efficient generation, transmission and use of energy. Materials developments are crucial to progress in all these areas: to innovation in design; to extending lifetime and maintenance intervals; and to successful operation in more demanding environments. Drawing together the broad community with interests in these areas, Energy Materials addresses materials needs in future energy generation, transmission, utilisation, conservation and storage. The journal covers thermal generation and gas turbines; renewable power (wind, wave, tidal, hydro, solar and geothermal); fuel cells (low and high temperature); materials issues relevant to biomass and biotechnology; nuclear power generation (fission and fusion); hydrogen generation and storage in the context of the 'hydrogen economy'; and the transmission and storage of the energy produced.

As well as publishing high-quality peer-reviewed research, Energy Materials promotes discussion of issues common to all sectors, through commissioned reviews and commentaries. The journal includes coverage of energy economics and policy, and broader social issues, since the political and legislative context influence research and investment decisions.

\section{CALL FOR PAPERS}

Contributions to the journal should be submitted online at http://ema.edmgr.com

To view the Notes for Contributors please visit: www.maney.co.uk/journals/notes/ema

Upon publication in 2006, this journal will be available via the Ingenta Connect journals service. To view free sample content online visit: www.ingentaconnect.com/content/maney

For further information please contact:

Maney Publishing UK

Tel: +44 (0)113 2497481 Fax: +44 (0)1132486983 Email: subscriptions@maney.co.uk

or

Maney Publishing North America

Tel (toll free): 8662975154 Fax: 6173546875 Email: maney@maneyusa.com

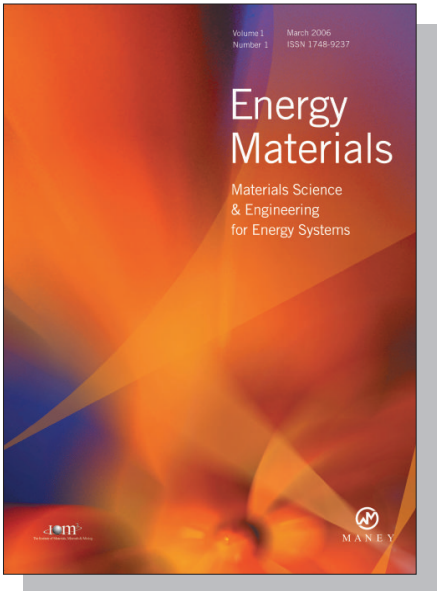

EDITORS

Dr Fujio Abe

NIMS, Japan

Dr John Hald, IPL-MPT, Technical University of Denmark, Denmark

Dr R Viswanathan, EPRI, USA

\section{SUBSCRIPTION INFORMATION}

Volume 1 (2006), 4 issues per year

Print ISSN: 1748-9237 Online ISSN: 1748-9245

Individual rate: $£ 76.00 / U S \$ 141.00$

Institutional rate: $£ 235.00 /$ US $\$ 435.00$

Online-only institutional rate: $£ 199.00 / U S \$ 367.00$

For special $\mathrm{IOM}^{3}$ member rates please email

subscriptions@maney.co.uk

\section{For further information or to subscribe online please visit www.maney.co.uk}



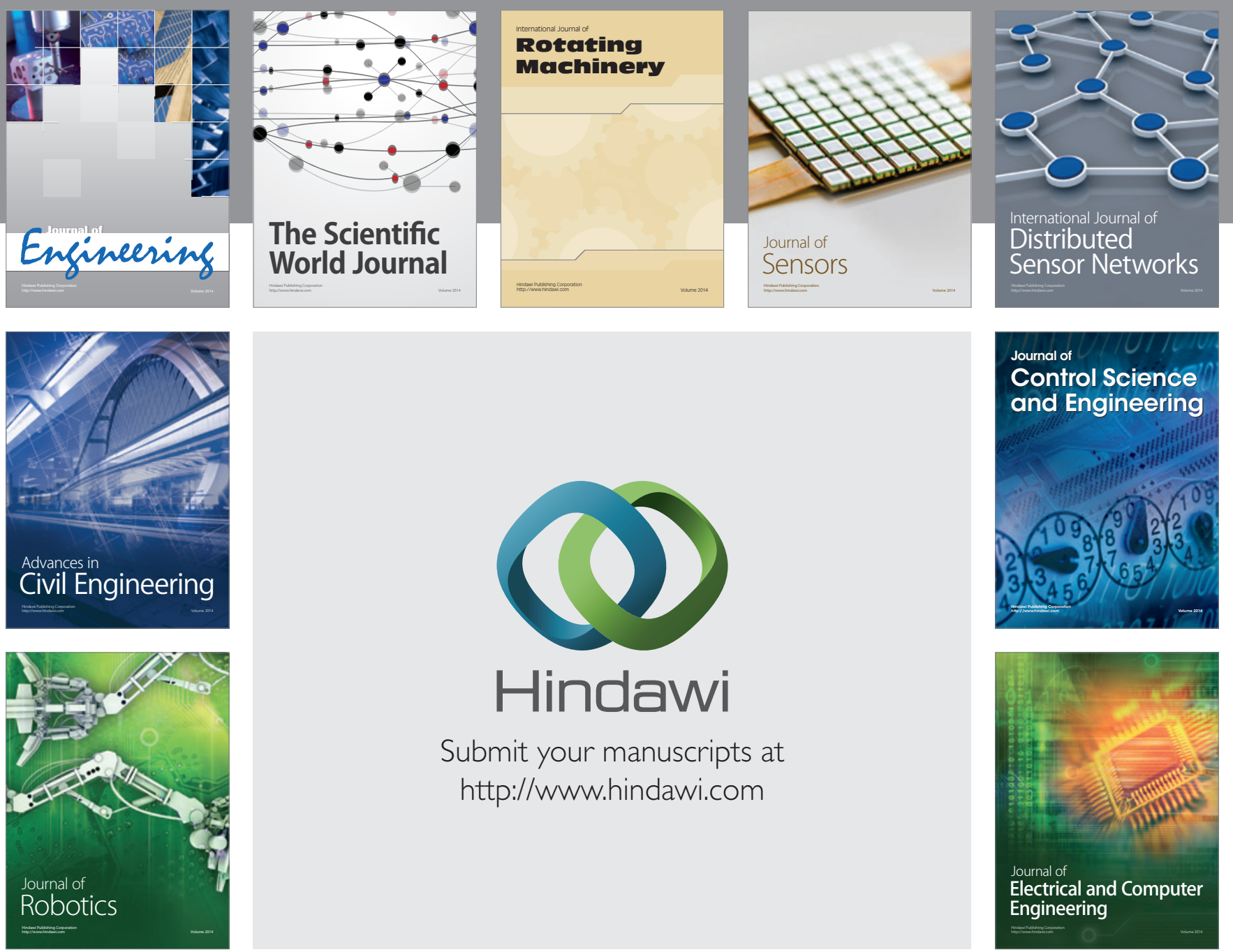

Submit your manuscripts at

http://www.hindawi.com
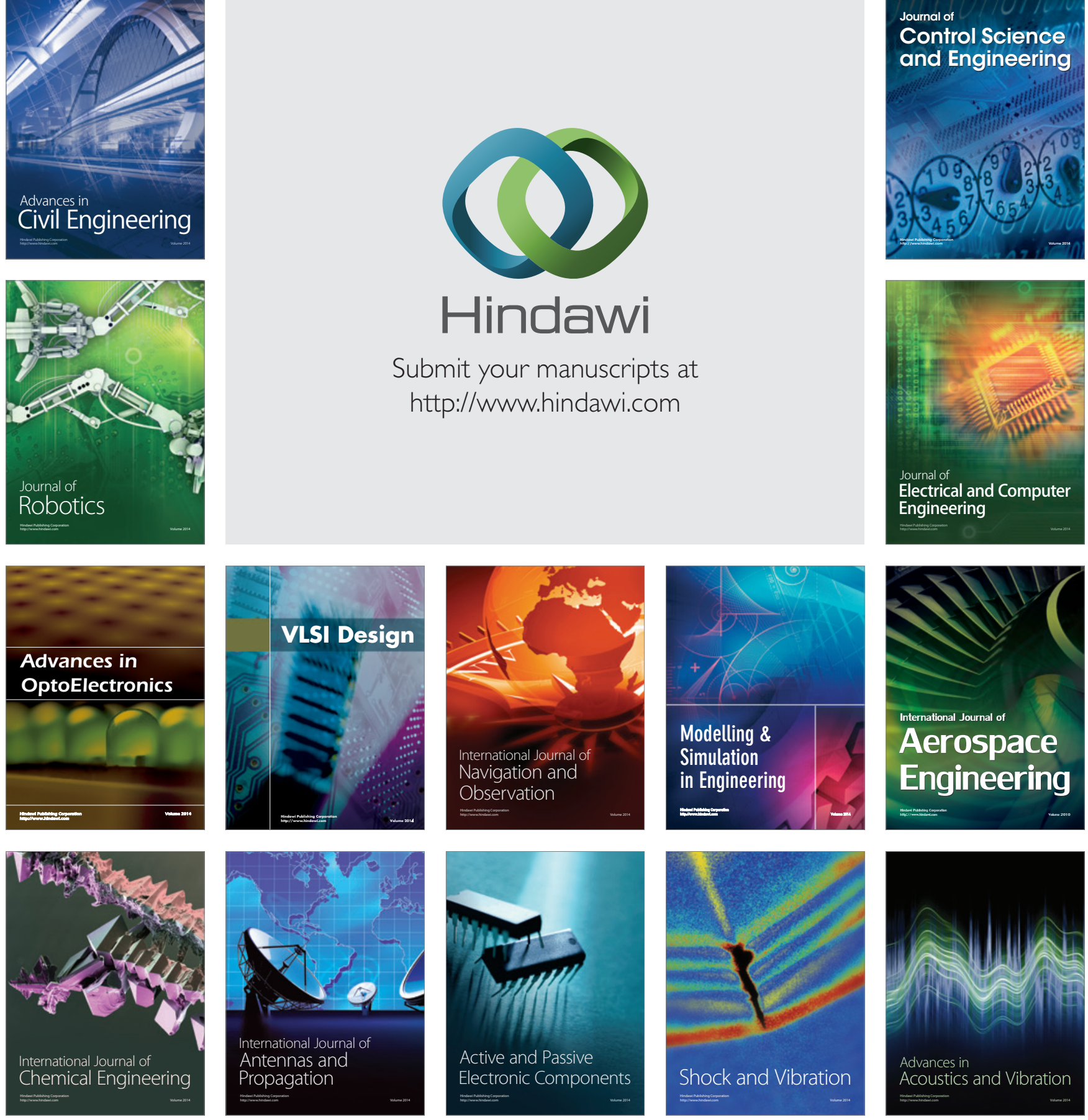